\title{
MAN.06 - Relevancy and applicability of Marketing activities and its strategic role by providing subsidies and support to key areas in Bio-Manguinhos
}

\author{
Linda Khalili Boukai ${ }^{\star *}$; Julia Schurig Figueiredo'; Denise Maria Lobo Crivelli ${ }^{1}$. \\ 1Fiocruz/Bio-Manguinhos.
}

Introduction: As per definition, Marketing activities are means and methods used by an unit to generate value, promoting renewal and growth to the market practices of an Institution. BioManguinhos' Marketing Function fulfills this premise, playing a key role in the Market Relations Department. To ensure relevancy and applicability to its activities, Marketing assignments interact with absolute connection to functional processes from Bio-Manguinhos' strategic areas, being entirely aligned with market strategies defined by the executive board. The impacts of Marketing activities are observed in long term, however the richness of information placed in availability and accessibility is crucial for recognition and analysis of the environments (internal/external) ,meaning a valuable tool to support decision-making actions related to Strategic Plan review.

Objective: Present Marketing activities in data collection analysis and practices to subsidize information of market trends for Workshops in Vaccines, Biopharmaceuticals and Reagents for Diagnosis, aiming at the review of Bio-Manguinhos' Strategic Plan by the executive board and related key areas.

Methodology: In 2018, the review of Bio-Manguinhos' Strategic Plan started with the determination of the new board of Directors to mobilize key areas to prepare the Institute for the future. Planning and Organization Advisory, proposed a methodology involving the organization of Workshops counting on the participation of specialists dedicated to building roadmaps, focusing on short/long term mapping of market and technological scenario for the next 10 years (2018-2027). In this context, Marketing Function played a crucial role in market prospection of technological trends aiming at renewal and provision of updated and reliable data from competitors for current products in portfolio and others in pipeline. The methodology involved the performance of dedicated research based on market reports, electronic database (Medtrack) and public websites. Business Development Division supported Marketing collaborating with prospective work.

Results: Data collection revealed evidences of a growing global market for Vaccines, Biopharmaceuticals and Reagents for Diagnosis. Vaccines' future market is accelerating, driven by increasing launches in new therapeutic areas and pediatric vacines. Total market is expected to reach US $\$ 49.27$ billion by 2022 , from US $\$ 34.30$ billion in 2017 , indicating a growth rate of $7.5 \%$. In the last 5 years Biopharmaceuticals have increased it's revenue in $70 \%$, with recognized growth in market share. The expected market size in 2025 is US $\$ 399,5$ billion. Biotechnology Reagents market expects a growth rate of 9.86\% over the period 2017-2025. The market size will reach US $\$ 122.7$ billion by 2025 . Data reveal new technological trends consisting of automation and multitests, and new horizons for clinical diagnosis such as oncology and genetic screening.

Conclusion: Bio-Manguinhos Marketing Function subsidizes and supports strategic actions providing meaningful information for mapping national and global scenarios, favouring the search for new opportunities and identifying competitive advantages for technological development or Technology Transfer of products updated with market trends.

Keywords: Marketing; Market trends; Technological trends 